\title{
EXPLORING THE ASSOCIATION BETWEEN ADOLESCENTS PARTICIPATION IN SPORT AND THEIR ATTACHMENT TO PARENT AND PEER
}

\author{
Saulius Šukys
}

Aušra Lisinskienė

Lithuanian Sports University, Lithuania

\begin{abstract}
This qualitative cross-sectional design study examine the association between adolescents' participation in sports activities and their attachment with parents and peers. A total of 1348 (716 female and 632 male) aged 12 to 16 completed questionnaire assessing attachment with parent and peer (trust, communication, alienation). This study showed that adolescents not participating in sports scored significantly lower on all Parent Attachment subscales when compared to adolescent athletes. The research also revealed that participation in sports has an effect on both Trust in Peers and Alienation from them. Boys scored significantly higher than girls did on Trust and Alienation with parents, while girls scored significantly higher than boys in terms of Peer attachment. Younger adolescent scored significantly higher on the Parent Attachment scale whereas senior adolescents scored higher on Trust with Peer.
\end{abstract}

Keywords: adolescent attachment with parents, attachment with peer, participation in sport, positive youth development in sports.

\section{Introduction}

One of the most important and significant theories in psychology that explores human behavior and emotion development is the Attachment Theory. Bowlby (1969) and Ainsworth, Blehar, Waters and Wall (1978) Attachment Theory claims that the psychological and behavioral effects of early parent-child relationship will affect the development of close relationships with other people in the future. According to the data of various researches, secure attachment develops in a child when parents take care of the child with affection and are psychologically and physically accessible to him or her. Consequently, the child feels accepted, understood, valued, and he or she is able to maintain affectionate relationships both within and beyond the family (Zbarauskaite, 2011). These children are can also be identified by their ability to control negative emotions (Gentzler et al., 2014), to interact with parents (Cai et al., 2013), and to interact with peers (Dykas et al., 2008). Children develop an insecure type of attachment when parents do not accept the child's emotions and needs, are insensitive, or are trying to over-control the child. In cases such as these, a child learns to disregard emotions and, in an attempt to avoid upsetting his or her parents, the child seeks to communicate less with them. In adolescence, these children underestimate the importance of emotions and feelings in a relationship 
(Zbarauskaitè, 2011). Insecurely attached children often have communication and behavioral problems (Van Petegem et al., 2013. The importance of secure attachments becomes prominent in adolescence when psychological and social changes due to the transfer from childhood to adulthood are taking place (Nawaz, 2011).

As adolescents spend increasing amounts of time away from their parents, the development of their personality is substantially impacted not only by their family life but also by peers (Arnon et al., 2008). For adolescents, it is essential to establish new or to strengthen the already existing relationships with peers (Nawaz, 2011). The environment of peers provides not only emotional support but also recognition, which is essential for the development of identity (Abraham \& Kerns, 2013).

In terms of leisure activity, researchers emphasize that sports activities are one of the most common forms of extracurricular activity among adolescents (Tomik et al., 2012). Previous research has revealed a range of positive effects that sports activities have on personality development in children. For instance, one study demonstrated that students' involvement in sports is negatively associated with student smoking (Fredricks \& Eccles, 2010). Additionally, more than other types of extra-curricular activities, sports contribute to better relations with peers (Malinuevo et al., 2010) and social competency (Carreres-Ponsoda et al., 2012).

Although the choice of sports activities can be based on a variety of reasons (Bailey, Cope\& Pearce, 2013), the family also plays an important role (Clarke \& Harwood, 2014). Children's engagement in sports can change their parents' attitudes towards sports activities, encourage them to be interested in sports, change family communication, allow parents to get acquainted with the new friends of their children, and may affect family leisure activities (Dorsch et al., 2009).

Considering the fact that there is a lack of research dealing with the attachment of adolescents to their parents and peers, especially in relationship with involvement in leisure sports activities, the aim of this study was to examine the links between adolescents' participation in sports activities and their attachment to parents and peers. The study also sought to establish adolescents' attachment with parent and peer considering the aspects of gender and age. We hypothesized that the attachment to parents and peers differs if adolescents who are involved in sports are compared to those who do not practice any sports. i.e., expression of relationship with parents and peers would be more prominent for adolescent athletes comparing with those adolescents who do not participate in sports. We also hypothesized that the attachment to parents and peers varies depending on the age and gender of an adolescent subject. 


\section{Methods}

Participants.A random sampleof school students aged 12 to 16 residing in Kaunas District (one of the largest in the country) was produced. Seven schools of general education within the Kaunas District were selected to participate. As a result, data from 1348 questionnaires was gathered. The student data collected in terms of gender are as follows: $\left.\mathrm{N}_{\text {females }}=716 ; \mathrm{N}_{\text {males }}=632\right)$ and age $\left(\mathrm{N}_{\text {aged12}}=\right.$ $243 ; \mathrm{N}_{\text {aged13 }}=219 ; \mathrm{N}_{\text {aged14 }}=238 ; \mathrm{N}_{\text {aged15 }}=277 ; \mathrm{N}_{\text {aged 16 }}=371$. In examining the data, the research subjects were divided into two age groups: early adolescent aged 12 to $14(n=700)$ and middle adolescent aged 15 to $16(n=648)$.

\section{Measures}

Children attachment to their parents and peerswas researched on the basis of the modified Inventory of Parent and Peer Attachment (IPPA) - Inventory of Parent and Peer Attachment - Revised (IPPA-R) (Gullone\& Robinson, 2005).

The questions included in the inventory assess the positive, negative and cognitive effects dimensions of adolescents' relationships with their parents and close friends. The positive effects are clearly expressed in the questions, such as: "My parents respect my feelings", "My friends accept me as I am". The negative results of relationships are revealed in such questions, for example: "I feel angry with my parents", "I wish I had different friends". The cognitive ones are conveyed with the ideas: "My parents help me understand myself better", "I can count on my friends to listen when something is bothering me".

For each of the twenty-eight items assessing parent attachment and the twenty-five items assessing peer attachment, respondents are required to rate the degree to which each item is true for them on a three-point scale ranging from "Almost always or always true" to "Almost never or never true." The items in each of the scales (i.e. parent, peer) were divided into three factors (trust; communication; anger and alienation). The total score for each of the IPPA-R Parent and Peer Attachment scales was calculated by obtaining a sum of the Trust and Communication subscales and then subtracting the Alienation subscale score (Gullone\& Robinson, 2005). Alpha coefficients showed good levels of internal consistency and ranged from .72 to .86 for the Parent Attachment scales, and from .71 to .86 for the Peer Attachment scales.

Student involvement in sportwas established by posing the question "Do you practice sports?" The research subjects had the following three choices: (a) "Yes, I actively practice sports, attend training practices and participate in competitions"; (b) "Yes, I practice sports in my free time so that to keep fit, but I do not attend regular sports practices and do not go for the highest sports results"; and (c) "I do sports activities only during physical education classes; I do no sports in my free time."

Data analysis. Descriptive statistics analyses and internal consistency of the IPPA-R was examined by conducting Cronbach's alpha analyses on each of the subscales. T test and ANOVA were computed to compare group differences. 
Correlational analyses were conducted to examine the interrelations among IPPA-R subscales. Hierarchical regression analyses were applied to examine the effects of independent study variables on attachment to parent and peer.

\section{Results}

It was established that Trust is the most prominently expressed subscale in children. When evaluating the attachment with peers, it was established that children scored higher on the Trust subscale, lower on the Communication, and the lowest on the Alienation scale. The overall Peer Attachment was higher than Parent Attachment.

Boys scored significantly higher than girls did on two scales of the Parent Attachment domain: Trust $(t=-2.12 ; p<.05)$ and Alienation $(t=-3.42 ; p<.001)$ (Table 1). Girls scored significantly higher than boys on Trust $(t=7.00$; $p<.001)$, Communication ( $t=13.23 ; p<.001)$, and Alienation $(t=3.42$; $p<.001)$ as well as overall Peer Attachment $(t=10.68 ; p<.001)$.

The age group differences were as follows: the early adolescent scored significantly higher on the Trust $(t=7.19 ; p<.001)$, Communication $(t=9.00$; $p<.001)$, and Alienation $(t=3.55 ; p<.001)$ subscales as well as on the overall Parent Attachment scale $(t=8.48 ; p<.001)$ when compared with the senior adolescent sample. In contrast, senior adolescents scored higher on one subscale of the Peer Attachment scale, Trust $(t=-2.13 ; p<.05)$.

The research revealed that $36.3 \%$ adolescents aged 12 to 16 attend sports practices and take part in competitions while $35.6 \%$ adolescents exercise in their free time. The remaining $28.1 \%$ do sports only during physical education classes. Furthermore, we investigated differences between adolescent participation in sports activities and their attachment with parents and peers (Table 2). We observed an association of participation in sports with the Trust $(F=13.27 ; p<.001)$, Communication $(F=11.85 ; p<0.001)$, and Alienation $(F=7.10 ; p<.01)$ subscales as well as overall Parent Attachment $(F=9.79$; $p<.001)$. The study also determined that participation in sports was associated with two issues covered in the Peer Attachment scale: Trust $(F=3.60 ; p<.05)$ and Alienation $(F=5.67 ; p<.01)$.

Additionally, the researchers conducted a multiple regression analysis to examine the effects of gender, age, and participation in sport on attachment to parent and peer. In each analysis, variables of gender, age, and participation in sport were included as independent variables, with attachment with parent and peer as dependent variables. Analyses showed that for adolescents Trust to parent is significantly impacted by age $(\beta=.18, p<.001)$ and participation in sport $(\beta=.12, p<.001)\left(F=24.70, p<.001\right.$, Adjusted $\left.R^{2}=.06\right)$. For the Communication with parents age $(\beta=.23, p<.001)$ and participation in sport $(\beta=.10, p<.001)$ were significant predictors $(F=32.01, p<.001$, Adjusted $\left.R^{2}=.07\right)$. All independent study variables of gender $(\beta=.08, p<.01)$, age 
$(\beta=.09, p<.01)$, and participation in sport $(\beta=.08, p<.01)$ were significant predictors for Alienation with parents $\left(F=10.80, p<.01\right.$, Adjusted $\left.R^{2}=.02\right)$. For the overall adolescents' attachment with parents, significant predictors wereage $(\beta=.21, p<.001)$ and participation in sport $(\beta=.10, p<.001$, $F=28.64, p<.001$, Adjusted $\left.R^{2}=.06\right)$.

Table 1. Means and Standard deviations for the IPPA-R by gender and age $(N=1348)$

\begin{tabular}{|c|c|c|c|c|c|c|c|c|}
\hline \multirow{3}{*}{ Measure } & \multicolumn{4}{|c|}{ Gender } & \multicolumn{4}{|l|}{ Age } \\
\hline & \multicolumn{2}{|c|}{ Girls $(n=716)$} & \multicolumn{2}{|c|}{ Boys $(n=632)$} & \multicolumn{2}{|c|}{$\begin{array}{l}12-14 \\
(n=700)\end{array}$} & \multicolumn{2}{|c|}{$\begin{array}{l}15-16 \\
(n=648)\end{array}$} \\
\hline & $\mathrm{M}$ & SD & $\mathrm{M}$ & SD & $\mathrm{M}$ & SD & $\mathrm{M}$ & SD \\
\hline \multicolumn{9}{|l|}{ IPPA-R-Parents } \\
\hline Trust & 23.83 & 3.35 & 24.21 & $3.02 *$ & 24.62 & 2.91 & 23.38 & $3.38 * * *$ \\
\hline Communication & 16.69 & 3.11 & 16.60 & $2.85 \mathrm{~ns}$ & 17.33 & 2.81 & 15.90 & $3.01 * * *$ \\
\hline Alienation & 16.38 & 2.58 & 16.86 & $2.55 * * *$ & 16.85 & 2.55 & 16.35 & $2.58 * * *$ \\
\hline Total score & 24.15 & 4.92 & 23.95 & $4.66 \mathrm{~ns}$ & 25.09 & 4.58 & 22.94 & $4.78 * * *$ \\
\hline \multicolumn{9}{|l|}{ IPPA-R-Peers } \\
\hline Trust & 26.08 & 3.80 & 24.61 & $3.90 * * *$ & 25.17 & 4.03 & 25.63 & $3.78 *$ \\
\hline Communication & 19.27 & 3.33 & 16.85 & $3.35 * * *$ & 18.05 & 3.50 & 18.24 & $3.60 \mathrm{~ns}$ \\
\hline Alienation & 9.62 & 1.43 & 9.35 & $1.48 * * *$ & 9.42 & 1.47 & 9.57 & $1.45 \mathrm{~ns}$ \\
\hline Total score & 35.73 & 6.05 & 32.12 & $6.35 * * *$ & 33.80 & 6.56 & 34.29 & $6.32 \mathrm{~ns}$ \\
\hline
\end{tabular}

Note. ${ }^{*}-p<0.05 ;{ }^{* *}-p<0.001 ; n s=$ not significant.

Table 2. Means and Standard deviations for the IPPA-R in terms of participation in sports activities $(\mathrm{N}=1348)$

\begin{tabular}{lcccccc}
\hline & \multicolumn{2}{l}{$\begin{array}{l}\text { Attend regular } \\
\text { practices of some } \\
\text { sports (n=489) }\end{array}$} & $\begin{array}{l}\text { Exercise in their } \\
\text { leisure time } \\
(\mathrm{n}=480)\end{array}$ & \multicolumn{2}{l}{$\begin{array}{l}\text { Exercise only during } \\
\text { classes of physical } \\
\text { education }(\mathrm{n}=379)\end{array}$} \\
\cline { 2 - 7 } IPPA-R-Parents & $\mathrm{M}$ & $\mathrm{SD}$ & $\mathrm{M}$ & $\mathrm{SD}$ & $\mathrm{M}$ & $\mathrm{SD}$ \\
\cline { 2 - 7 } & & & & & & \\
\hline Trust & 24.44 & 3.00 & 24.08 & 3.06 & 23.33 & $3.58^{\mathrm{ab} * * *}$ \\
Communication & 16.97 & 2.94 & 16.78 & 2.90 & 16.02 & $3.13^{\mathrm{ab} * * *}$ \\
Alienation & 16.85 & 2.52 & 16.67 & 2.45 & 16.20 & $2.75^{\mathrm{a} * * * \mathrm{~b} *}$ \\
Total score & 24.57 & 4.82 & 24.19 & 4.50 & 23.15 & $5.12^{\mathrm{ab} * * *}$ \\
IPPA-R-Peers & & & & & & \\
Trust & 25.61 & 3.78 & 25.56 & 3.72 & 24.95 & $4.29^{\mathrm{a} *}$ \\
Communication & 18.14 & 3.34 & 18.37 & 3.51 & 17.87 & $3.85 \mathrm{~ns}$ \\
Alienation & 9.56 & 1.44 & 9.60 & 1.42 & 9.29 & $1.52^{\mathrm{a} * \mathrm{~b} * *}$ \\
Total score & 34.19 & 6.21 & 34.32 & 6.23 & 33.53 & $6.99 \mathrm{~ns}$ \\
\hline
\end{tabular}

Note. ${ }^{*}-p<0.05 ; * *-p<0.01 ; * * *-p<0.001 ; n s=$ not significant.

$a=$ significant differences comparing individuals not participating in sport with athletes. $b=$ significant differences comparing individuals not participating in sport with individuals leading the active leisure lifestyle. $c=$ significant differences comparing athletes with individuals leading the active leisure lifestyle

Analyses showed that all study variables of gender $(\beta=.20, p<.001)$, age $(\beta=.07, p<.01)$ and sport participation $(\beta=.10, p<.001)$ were significant 
predictors for adolescents Trust to peers $\left(F=22.46, p<.001\right.$, Adjusted $\left.R^{2}=.06\right)$. Gender $(\beta=.35, p<.001)$ and sport participation $(\beta=.08, p<.01)$ was also a significant predictor for adolescents Communication with peers $(F=61.94$, $p<.001$, Adjusted $\left.R^{2}=.12\right)$. A significant impact of gender $(\beta=.11, p<.001)$, age $(\beta=.06, p<.05)$, and sport participation $(\beta=.08, p<.09)$ was established $\left(F=8.81, p<.001\right.$, Adjusted $\left.R^{2}=.02\right)$ for the Alienation with peers. Our results demonstrate that gender $(\beta=.29, p<.001)$ and participation in sport $(\beta=.08$, $p<.01)$ had significant relations with adolescents overall attachment with peers $\left(F=42.09, p<.001\right.$, Adjusted $\left.R^{2}=.09\right)$.

\section{Discussion}

In this study we aimed to determine the link between the involvement of adolescents in sports activity and their attachment to their parents and peers. We also aimed to establish adolescents' attachment with parent and peer considering the aspects of gender and age. While investigating the development of attachment to parents and peers in dependence with the adolescents' age, we discovered that Trust, Communication, and Alienation from parents are more prominent in junior adolescents in comparison to senior adolescents. Scholars (Arnon et al., 2008, Dykas et al., 2008) highlight that adolescents' attachment to parents undergoes development as children become increasingly less dependent on their parents. Hence, attachment to their parents may be less important for senior adolescents. Our research demonstrates that senior adolescents aged 15 to 16 exhibits a more intensive manifestation of Trust as well as Alienation with Peer in comparison with junior adolescents. The findings shows that adolescent and peer attachment influence a wide array of psychosocial phenomena, including interpersonal relationships. The expression of Trust are important for children's success in peer relationships. At the same time Alienation lead them to become less committed, unsatisfied, and more adverse within their relationships. Our results highlight how attachment between senior adolescence and peers can contribute to understanding how close personal relationships vary in quality.

Furthermore, we sought to discover the dependence of adolescent Attachment to their parents and peers regarding the criterion of gender. The results showed that boys manifest both Trust and Alienation from parents more intensively than girls do. However, the intensity of Communication with parents was found to be of equal value for both genders. It should be observed that research conducted in other countries (Nawaz, 2011, Imtiaz \& Naqvi, 2012) yielded totally different results; statistically significant gender-based differences observed illustrated that girls appeared to be far more attached to their parents than boys. It is likely that the difference in results may have been caused by the cultural differences of the research countries; this issue has been noted by a number of scholars dealing with attachment (Imitiaz \& Naqvi, 2012). 
In terms of the impact of gender on adolescent relationship with peers, our research revealed that the relationship of girls with peers on all scales - Trust, Communication, and Alienation - was expressed more prominently than in boys. In this way, the relevant hypothesis set at the beginning of this research was proven positive; girls find the environment of peers to be much more important than that of parents. Most likely, it is much more important for girls to express themselves in the environment of friends at the age of adolescence.

The data of the research conducted by Engels, Dekovic and Meeus (2002) showed that the quality and intensity of the attachment of adolescents to their peers depends on the importance of the relationship in the family and the attachment to their parents. The research of the aforementioned scholars shows that for adolescents, insecure attachment to parents is related with the increased strife to express themselves among peers. However, other research (Dykas et al., 2008) show that adolescent who are insecurely attached to their parents find it much harder to gain recognition among their peers.

We further explored whether the attachment to parents and peers is dependent on whether adolescents practice sports intensively, leisurely, or not at all. We discovered that the expression of the relationship with parents on all scales - Trust, Communication, and Alienation - is much more intense in the adolescents who attend sports practices and go for results in competitions than in those adolescents who do not attend practices and do not exercise. A more intensive expression of relationships on all scales is more prominent not only in those adolescents who go for results in sports but also in those who prefer active leisure activities related to sports. Research by Carr (2009) also proved that secure relationship among adolescents and their parents prominently depend on the positive interaction of the parents and adolescents in the sports environment. Among adolescents attending sports practices and seeking results, the expression of relationship with peers was more prominent on the scales of Trust and Alienation in comparison with those adolescents who do not participate in sports. The manifestation of Alienation is the least prominent in those adolescents who only do sports in their leisure time or do not do any sports at all. Thus, our hypothesis that the attachment to parents and peers differs depending on the adolescents being involved or not being involved in sports was proven correct.

When discussing the obtained results, attention should be paid to findings of other scholars discussing the role of parents in the sports activities of their children. It has been found that adolescents' approach to sports activities is related to their parents' point of view (LaVoi \& Stellino, 2008). Furthermore, other research has revealed that parents influence their children's motivation to participate in sports (Sánchez-Miguel et al., 2013) and their choice of sports activities (Dorsch et al., 2009). On one hand, this finding is not surprising since children's participation in sports often involves their parents (Dorsch et al., 2009). This may explain higher trust and communication with parents in relation 
to adolescents who do or do not participate in sports. On the other hand, parents may demotivate their children's sports activity by demanding that they participate and seek results in sports. In this case, the opposite result is likely to be found when assessing the attachment between parents and children.

In considering the interaction of children involved in sports and their parents, attention must also be paid to differences in the roles of mothers and fathers in promoting sports activities (Palomo-Nieto et al., 2011). Hence, future research should investigate not only the attachment of adolescents to parents in general but also separately in relation to fathers and mothers.

\section{Conclusion}

This study determined that boys scored higher than girls did on Trust and Alienation with parents, while girls scored higher than boys in terms of Peer attachment. Younger children scored statistically significantly higher on the Parent Attachment scale whereas senior adolescents scored higher on Trust with Peers. The research revealed the effect of participation in sports on Attachment to Parents. The research also revealed that participation in sports has an effect on both Trust in Peers and Alienation from them.

\section{References}

Abraham, M. M, Kerns, K. A. (2013). Positive and negative emotions and coping as mediators of mother-child attachment and peer relationships. Merrill-Palmer Quarterly, 59, 399-425.

Ainsworth, M. D. S, Blehar, M. C, Waters, E, Wall, S. (1978). Patterns of attachment: A psychological study of the strange situation. Hillsdale, NJ: Erlbaum.

Arnon, S., Shamai, S., Illatov, Z. (2008). Socialization agents and activities of young adolescents. Adolescence, 43, 373-397.

Bailey, R., Cope, E.J., Pearce, G. (2013). Why do children take part in, and remain involved in sport? A literature review and discussion of implications for sports coaches. International Journal of Coaching Science, 7, 56-75.

Bowlby, J. (1969). Attachment and loss. New York, NY: Basic Books.

Cai, M., Hardy, S. A., Olsen, J. A., Nelson, D. A., Yamawaki, N. (2013). Adolescent-parent attachment as a mediator of relations between parenting and adolescent social behavior and wellbeing in China. International Journal of Psychology, 48, 1185-1190.

Carr, S. (2009). Adolescent-parent attachment characteristics and quality of youth sport friendship. Psychology of Sport \& Exercise, 10, 653-664.

Carreres-Ponsoda, F., Carbonell, A.E., Cortell-Tormo, J.M., Fuster-LLoret, V., Andreu-Cabrera, E. (2012).The relationship between out-of-school sport participation and positive youth development. Journal of Human Sport \& Exercise, 7, 671-683.

Clarke, N. J., Harwood, Ch. G. (2014). Parenting exercise experiences in elite youth football: A phenomenological study. Psychology of Sport and Exercise, 15, 528-537.

Dykas, M. J., Ziv, Y., Cassidy, J. (2008). Attachment and peer relations in adolescence. Attachment and Human Development, 10, 123-141.

Dorsch, T. E., Smith, A. L., McDonough, M.H. (2009). Parents' perceptions of child-toparent socialization in organized youth sport. Journal of Sport and Exercise Psychology, $31,444-468$. 
Engels, R., Dekovic, M., Meeus, W. (2002). Parenting practices, social skills and peer relationships in adolescence. Social Behavior and Personality, 30, 3-18.

Fredricks, J. A., Eccles, J. S. (2010). Breadth of extracurricular participation and adolescent adjustment among African-American and European-American youth. Journal of Research on Adolescence, 20, 307-333.

Gentzler, A. L., Ramsey, M. A., Yuen Y. C., Palmer, C. A., Morey, J. N. (2014). Young adolescents' emotional and regulatory responses to positive life events: investigating temperament, attachment, and event characteristics. Journal of Positive Psychology, 9, $108-121$.

Gullone, E., Robinson, M. (2005). The Inventory of Parent and Peer Attachment-Revised (IPPA-R) for Children: A Psychometric Investigation. Clinical Psychology and Psychotherapy, 12, 67-79.

Imtiaz, S., Naqvi, I. (2012).Parental attachment and identity styles among adolescents: Moderating role of gender. Pakistan Journal of Psychological Research, 27, 241-264.

LaVoi, N. M., Stellino, M. B. (2008). The influence of perceived parent created sport climate on competitive youth male hockey players' good and poor sport behaviors. Journal of Psychology: Interdisciplinary \& Applied, 142, 471-495.

Malinuevo, B., Bonillo, A., Pardo, Y., Doval, E., Torrubia, R. (2010).Participation in extracurricular activities and emotion and behavioral adjustment in middle childhood in Spanish boys and girls. Journal of Community Psychology, 38, 842-857.

Nawaz, S. (2011). The relationship of parental and peer attachment bonds with the identity development during adolescence. Journal of Social Sciences, 5, 104-119.

Palomo-Nieto, M., Rui-Pérez, L. M., Sánchez-Sánchez, M., García-Coll, V. (2011).Young athletes' perceptions of the role of their mothers in their sport career.European Journal of Human Movement, 26, 141-157.

Sánchez-Miguel, P. A., Leo, F. M., Sánchez-Oliva, D. et al. (2013). The Importance of parents' behavior in their children's enjoyment and amotivation in sports. Journal of Human Kinetics, 36, 171-179.

Tomik, R., Olex-Zarychta, D., Mynarski, W. (2012). Social values of sport participation and their significance for youth attitudes towards physical education and sport.Studies in Physical Culture and Tourism, 19, 99-104.

Van Petegem, S., Beyers, W., Brenning, K., Vansteenkiste, M. (2013). Exploring the association between insecure attachment styles and adolescent autonomy in family decision making: A differentiated approach.Journal of Youth and Adolescence, 42, 1837-1846.

Zbarauskaitè, A. (2011). Prieraišumas: Iššūkiai ir galimybès globojant vaika ir paaugli. Vilnius: Valstybès vaiko teisių apsaugos ir įvaikinimo tarnyba. 